Relations industrielles

Industrial Relations

\title{
Work in Traditional and Modern Society, by Stanley H. Udy, Jr., New Jersey, Prentice-Hall Inc., Englewood Cliffs, 1970, 134 pp.
}

\section{Laurent Bélanger}

Volume 25, numéro 3, 1970

URI : https://id.erudit.org/iderudit/028166ar

DOI : https://doi.org/10.7202/028166ar

Aller au sommaire du numéro

Éditeur(s)

Département des relations industrielles de l'Université Laval

ISSN

0034-379X (imprimé)

1703-8138 (numérique)

Découvrir la revue

Citer ce compte rendu

Bélanger, L. (1970). Compte rendu de [Work in Traditional and Modern Society, by Stanley H. Udy, Jr., New Jersey, Prentice-Hall Inc., Englewood Cliffs, 1970, 134 pp.] Relations industrielles / Industrial Relations, 25(3), 625-625.

https://doi.org/10.7202/028166ar

Tous droits réservés @ C Département des relations industrielles de l'Université Laval, 1970
Ce document est protégé par la loi sur le droit d'auteur. L'utilisation des services d'Érudit (y compris la reproduction) est assujettie à sa politique d'utilisation que vous pouvez consulter en ligne.

https://apropos.erudit.org/fr/usagers/politique-dutilisation/ 
changement technologique et le développement humain. Cette conférence était commanditée entre autres, par les fondations américaines et britanniques sur l'automation et l'emploi. Le but de ces organismes est d'étudier la nature des changements technologiques et leurs conséquences économiques (variations dans les niveaux d'emploi, effets sur les structures du marché du travail, distribution du revenu et industrialisation) et sociologiques (déplacements de main-d'oeuvre, syndicalisme, qualité du travail humain et éducation).

Voici quelques titres d'articles présentés dans ce volume: "Le rôle de la technologie moderne pour rehausser les standards économiques des pays sousdéveloppés 》, 《Modification des compétences, formation, motivation et mobilité 》, 《Réorientation des attitudes patronales, syndicales et ouvrières vers un nouveau contenu de la tâche », 《Le futur de la négociation collective et la résolution des conflits industriels », « Politique de revenu et partage des gains de capitaux », «La participation des travailleurs israéliens à l'entreprise, au syndicat et au gouvernement », «Le rôle de la compagnie internationale », «le rôle social du syndicat».

Ce volume nous livre la pensée d'un groupe d'hommes d'action et de théoriciens (économistes, leaders de groupes minoritaires, industriels, leaders syndicaux, professionnels dans le champs de la négociation collective, de la médiation et de l'arbitrage, officiers gouvernementaux de trois pays) sur un sujet crucial pour tout pays : celui des changements technologiques et de leur planification. Il nous donne ensuite une information comparative sur des sujets majeurs en relations patronales ouvrières et en relations de travail. Enfin, tout cela est appuyé par des exemples vécus en Israël, laboratoire moderne d'industrialisation et de changement technologique.

\section{Lola JACQUES}

\section{Work in Traditional and Modern Society,} by Stanley H. Udy, Jr., New Jersey, Prentice-Hall Inc., Englewood Cliffs, 1970, $134 \mathrm{pp}$.

D'une part, la sociologie industrielle s'intéresse à la structure et au fonctionnement des organisations de travail; d'autre part, la sociologie du dévelop- pement économique et social s'intéresse aux sociétés en voie d'industrialisation et d'organisation. L'ouvrage de Stanley H. Udy dans la série intitulée Modernisation des sociétés traditionnelles tente d'établir un pont entre les deux perspectives sociologiques. Son point de départ consiste en un modèle qui se veut une représentation symbolique des liens qui peuvent exister entre les formes d'organisation de travail que des sociétés se donnent et les différents stages de leur développement. $\mathrm{Ce}$ modèle permet d'étudier plus précisément l'impact que des formes différentes de travail organisé peuvent avoir sur le passage de la société traditionnelle à la société industrielle et post-industrielle. L'exploration de ce lien incite l'auteur à formuler deux hypothèses de travail: il est possible que des formes existantes de travail organisé dans toute société affectent son potentiel de développement économique et social; il est aussi vraisemblable qu'un stage donné de développement économique et social influence la manière dont le travail sera probablement organisé dans une société. Après avoir défini les concepts de 《développement social » et de «travail organisé » et après avoir élaboré son modèle, l'auteur procède à l'étude de 359 organisations dans 125 sociétés différentes pour arriver à jeter plus de lumière sur ses hypothèses de départ. En plus d'être immédiatement utile au sociologue de profession, cet ouvrage intéresse aussi les spécialistes des relations industrielles qui veulent améliorer leur compréhension des contextes socio-économiques et culturels dans lesquels se façonnent ou se détériorent les rapports collectifs du travail.

\section{Laurent BELANGER}

\section{Participation Achievement and Involve-} ment on the Job, by Martin Patchen, New Jersey, Prentice-Hall Inc., Englewood Cliffs, 1970, 285 pp.

Ce volume est la publication d'une recherche sur la motivation au travail menée à la Tennessee Valley Authority.

Il constitue à lui seul trois volumes en un. C'est d'abord un exposé théorique élargi et enrichi sur des sujets pertinents à la psycho-sociologie comme la motivation, l'identification à l'organisation et au groupe de travail, la participation la prise de décision, l'accomplissement et l'engagement personnel au travail. 